DVD directed by filmmaker Nettie Wild, documents the activities of the nurses of the British Columbia Centre for Disease Control in Vancouver's Downtown Eastside.

As most CMAJ readers will know, in Canada's poorest postal code neighbourhood the crowded conditions in the single room occupancy hotels, shelters, and abandoned buildings set the stage for social network conditions that have contributed to a public health nightmare. In these environments, drug addicts mix with the mentally ill and the homeless while scraping out their next fix by whatever means available, often through a bustling survival sex-trade industry. Not surprisingly, deep in the decaying buildings and filthy alleyways, rates of human immunodeficiency virus, tuberculosis, syphilis and hepatitis $\mathrm{C}$ are among the highest in the country. Into this Dickensian quagmire wade the Centre's nurses to extend the reach of the public health system.

While a host of medical and social needs are addressed daily by the nursing team, as demonstrated in the Bevel Up DVD, the primary activities of the nurses are giving out clean needles and condoms, attending to minor medical concerns, taking blood samples for HIV and other testing, and teaching drug users how to inject themselves safely to avoid injury and reduce the spread of infectious disease. The 45-minute video follows the team of nurses going about their daily routine. Many of the images are gutwrenching. In one scene, the nurses find a mother with her teenage daughter living hidden underneath a trailer at the back of one of the alleys. The mother, who is deathly ill with pneumonia, is addicted to heroin and her pregnant daughter is addicted to crack cocaine. The nurses climb behind the trailer to talk to the women, and eventually secure the pair housing in a temporary shelter

The DVD also contains a series of teaching chapters in which a host of respected Canadian experts address everything from the ethics of harm reduction nursing to the legal issues these nurses face. These seemingly lofty issues are daily concerns facing health workers who patrol the alleys teaching drug users how to inject themselves properly (hence, "bevel up"), and are particularly relevant

\title{
Poem
}

\section{Hearts and minds}

Lost keys: the thousandth time. I check your pockets,

the truck, wallet, walkway, yesterday's clothes.

Hours of this, hours of me turning your pockets

inside out, of retracing the day you can't remember,

a strange kind of refusal. I wear my best graveclothes

in search of your heart, which strains against

what the doctor in his little room says is heart failure,

and your brain, which we can see is a struggle

for keys. And you always look like I can unlock,

You always find them, you say. I curse

you for the thousandth time, forced to tie a stick

to the keys in a trick I learned from a gas station;

and my love is a big stick, is a battery of tests,

is the track of your mind thirty years ago,

is finding the key in the oven, or propping up

$\approx$ the tippy kitchen table, or in the tub as a float toy

for my daughter, and your refusal that it ever

could have been there, I found it.

\section{Shane Neilson MD \\ Family physician \\ Guelph, Ont.}

in light of the current political climate in which this work takes place. These educational chapters will be of widespread interest beyond the field of nursing. In one chapter, University of British Columbia neurologist Anthony Phillips describes the biological effects of different drugs on the brain, while in another drug users themselves demonstrate first-hand what different drugs look like. The viewer is left with the overall impression that society's response to the drug problem is certainly misguided.

Although it received less than 5\% of federal funding under Canada's prior drug strategy, harm reduction was included as a key "pillar" in the effort and was supported by a transparent and multi-stakeholder consultative process led by Health Canada and the Canadian Centre on Substance Abuse. The former strategy underscored the importance of harm reduction measures "to limit possible secondary effects of substance use, such as the spread of HIV/AIDS and hepatitis C." Remarkably, the Harper government ignored this consultative process, as well as the recommendations of international sci- entific bodies such as the World Health Organization, and excluded harm reduction from its new Anti-Drug Strategy in 2007.

Despite the Tories' treatment of evidence-based public health, the activities of the nurses at the British Columbia Centre for Disease Control have continued. Bevel Up's presentation of the reality confronted by the nurses on the Downtown Eastside's gritty streets pulls back the curtain of ignorance shrouding the Harper government's approach to illicit drugs - witness Health Minister Tony Clement's statement that "law enforcement is harm reduction." While Bevel Up will be informative to anyone interested in evidence-based approaches to drug addiction, it should be required viewing for nursing and medical students across the country. Someone should also send a copy to the Prime Minister's office.

\section{Evan Wood MD PhD \\ British Columbia Centre for \\ Excellence in HIV/AIDS \\ St. Paul's Hospital \\ Vancouver, BC}

